\title{
A COMPUTER SIMULATION APPROACH TO REDUCE APPOINTMENT LEAD-TIME IN OUTPATIENT PERINATOLOGY DEPARTMENTS: A CASE STUDY IN A MATERNAL-CHILD HOSPITAL
}

Ortiz-Barrios, M., Jiménez-Delgado, G., De Ávila-Villalobos, J.

\begin{abstract}
A significant problem in outpatient perinatology departments is the long waiting time for pregnant women to receive an appointment. In this respect, appointment delays are related to patient dissatisfaction, no shows and sudden infant death syndrome. This paper aims to model and evaluate improvement proposals to outpatient care delivery by applying computer simulation approaches. First, suitable data is collected and analyzed. Then, a discrete-event simulation (DES) model is created and validated to determine whether it is statistically equivalent to the current system. Afterward, the average appointment lead-time is calculated and studied. Finally, improvement proposals are designed and pretested by simulation modelling and statistical comparison tests. A case study of an outpatient perinatology department from a maternal-child is shown to validate the effectiveness of DES to fully understand and manage healthcare systems. The results evidenced that changes to care delivery can be effectively assessed and appointment lead-times may be significantly reduced based on the proposed framework within this paper.
\end{abstract}

\section{Keywords}

Discrete-event simulation (DES), Healthcare, Outpatient care appointment leadtime, Perinatology. 